\title{
ERRATA
}

\section{Morphological Effects of Lipopeptides against Aspergillus fumigatus Correlate with Activities against (1,3)- $\beta$-D-Glucan Synthase}

M. B. KURTZ, I. B. HEATH, J. MARRINAN, S. DREIKORN, J. ONISHI, AND C. DOUGLAS

Merck Research Laboratories, Rahway, New Jersey 07065, and York University, North York, Ontario, Canada

Volume 38, no. 7, p. 1481, column 1: Figure 1 should appear as shown below.

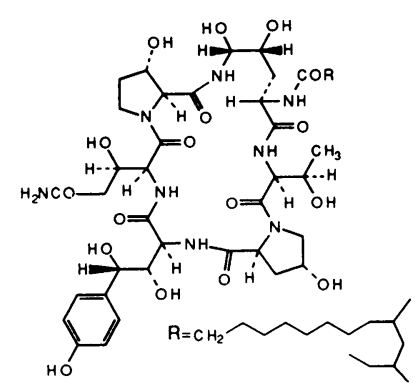

Pneumocandin $\mathbf{B}_{0}$

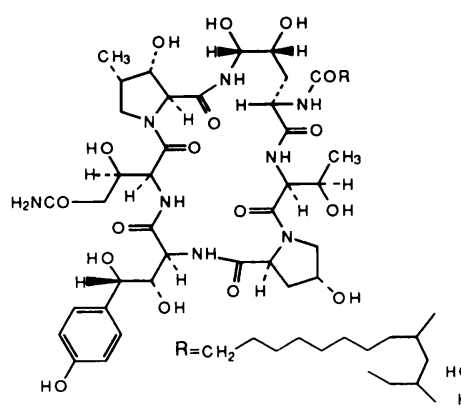

Pneumocandin Ao

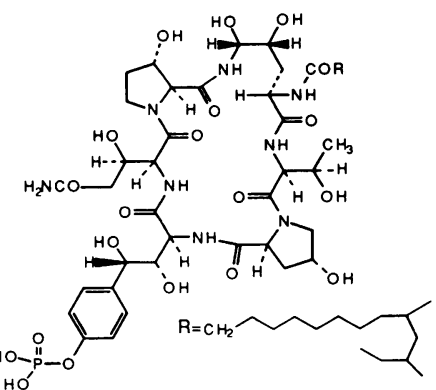

L-693,989

Page 1486, column 2, line 14 from bottom: Should read "[substrate] versus [substrate]/velocity ..."

Page 1488, column 1, reference 2, line 4: Should read "Synthesis, stability, and biological evaluation of water-soluble prodrugs of a new echinocandin lipopeptide. Discovery of a potential clinical agent for the treatment of systemic candidiasis and Pneumocystis carinii pneumonia (PCP). J. Med. Chem. 35:194-198."

\section{Comparison of Cefuroxime Axetil and Amoxicillin-Clavulanate Suspensions in Treatment of Acute Otitis Media with Effusion in Children} SAMUEL E. MCLINN, MICHAEL MOSKAL, JOHANNA GOLDFARB, FRANK BODOR, GERSON ARONOVITZ, RICHARD SCHWARTZ, PAMELA SELF, AND MICHAEL J. OSSI

Scottsdale Pediatrics, Scottsdale, Arizona 85260; Wilden Clinic, Des Moines, Iowa 50012; Rainbow Babies Hospital, Cleveland, Ohio 44106; Fairview Hospital, Cleveland, Ohio 44111; Pediatrics and Adolescent Medicine, Atlanta, Georgia 30329; and Vienna, Virginia 22180; and Glaxo Research Institute, Research Triangle Park, North Carolina 27709

Volume 38, no. 2, p. 316, column 1, lines 15 and 16: "500 mg/day" and "750 mg/day" should read " $1,000 \mathrm{mg} / \mathrm{day}$ " and " 1,500 $\mathrm{mg} /$ day," respectively. 